\title{
Transparent reporting of a multivariable prediction model for individual prognosis or diagnosis (TRIPOD): The TRIPOD statement
}

\author{
G S Collins ${ }^{*}, 1$ J B Reitsma ${ }^{2}$, D G Altman ${ }^{1}$ and K G M Moons ${ }^{2}$ \\ ${ }^{1}$ Centre for Statistics in Medicine, Nuffield Department of Orthopaedics, Rheumatology and Musculoskeletal Sciences, Botnar \\ Research Centre, University of Oxford, Oxford OX3 7LD, UK and ${ }^{2}$ Julius Center for Health Sciences and Primary Care, University \\ Medical Center Utrecht, PO Box 85500, 3508GA Utrecht, The Netherlands
}

\begin{abstract}
Prediction models are developed to aid health-care providers in estimating the probability or risk that a specific disease or condition is present (diagnostic models) or that a specific event will occur in the future (prognostic models), to inform their decision making. However, the overwhelming evidence shows that the quality of reporting of prediction model studies is poor. Only with full and clear reporting of information on all aspects of a prediction model can risk of bias and potential usefulness of prediction models be adequately assessed. The Transparent Reporting of a multivariable prediction model for Individual Prognosis Or Diagnosis (TRIPOD) Initiative developed a set of recommendations for the reporting of studies developing, validating, or updating a prediction model, whether for diagnostic or prognostic purposes. This article describes how the TRIPOD Statement was developed. An extensive list of items based on a review of the literature was created, which was reduced after a Web-based survey and revised during a 3-day meeting in June 2011 with methodologists, health-care professionals, and journal editors. The list was refined during several meetings of the steering group and in e-mail discussions with the wider group of TRIPOD contributors. The resulting TRIPOD Statement is a checklist of 22 items, deemed essential for transparent reporting of a prediction model study. The TRIPOD Statement aims to improve the transparency of the reporting of a prediction model study regardless of the study methods used. The TRIPOD Statement is best used in conjunction with the TRIPOD explanation and elaboration document. To aid the editorial process and readers of prediction model studies, it is recommended that authors include a completed checklist in their submission (also available at www.tripod-statement.org).
\end{abstract}

In medicine, patients with their care providers are confronted with making numerous decisions on the basis of an estimated risk or probability that a specific disease or condition is present (diagnostic setting) or a specific event will occur in the future (prognostic setting) (Box A). In the diagnostic setting, the probability that a particular disease is present can be used, for example, to inform the referral of patients for further testing, initiate treatment directly, or reassure patients that a serious cause for their symptoms is unlikely. In the prognostic setting, predictions can be used for planning lifestyle or therapeutic decisions based on the risk for developing a particular outcome or state of health within a specific period (Steyerberg, 2009; Moons et al, 2009b). Such estimates of risk can also be used to risk-stratify participants in therapeutic clinical trials (Hayward et al, 2006; Dorresteijn et al, 2011).

In both the diagnostic and prognostic setting, estimates of probabilities are rarely based on a single predictor (Riley et al, 2013). Doctors naturally integrate several patient characteristics and symptoms (predictors, test results) to make a prediction (see Box B for differences in common terminology between diagnostic and prognostic studies). Prediction is therefore inherently multivariable. Prediction models (also commonly called 'prognostic models,' 'risk scores,' or 'prediction rules' (Steyerberg et al, 2013) are tools that combine multiple predictors by assigning relative weights to each predictor to obtain a risk or probability (Steyerberg, 2009; Moons et al, 2009b). Well-known prediction

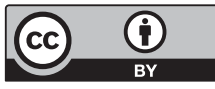




\section{Box A. Schematic representation of diagnostic and prognostic prediction modeling studies}

The nature of the prediction in diagnosis is estimating the probability that a specific outcome or disease is present (or absent) within an individual, at this point in time-that is, the moment of prediction $(T=0)$. In prognosis, the prediction is about whether an individual will experience a specific event or outcome within a certain time period. In other words, in diagnostic prediction, the interest is in principle a cross-sectional relationship, whereas prognostic prediction involves a longitudinal relationship. Nevertheless, in diagnostic modeling studies, for logistical reasons, a time window between predictor (index test) measurement and the reference standard is often necessary. Ideally, this interval should be as short as possible and without starting any treatment within this period.

Diagnostic multivariable modeling study
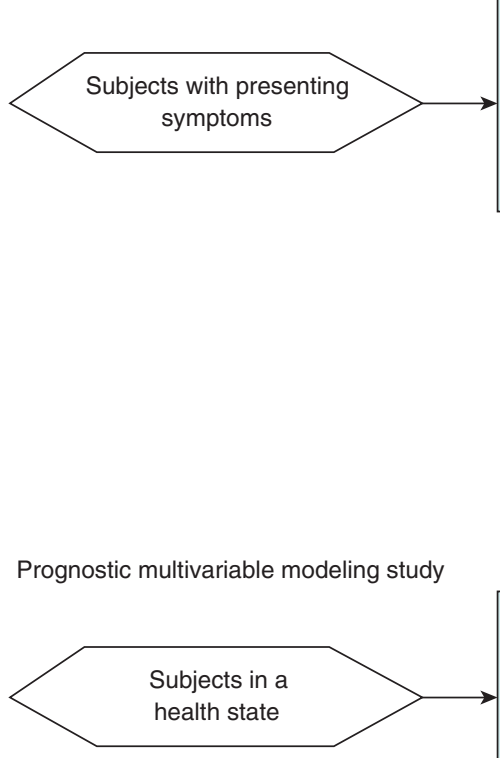

Predictors:

Patient characteristics

(symptoms \& signs)

Imaging tests

Laboratory tests

Others

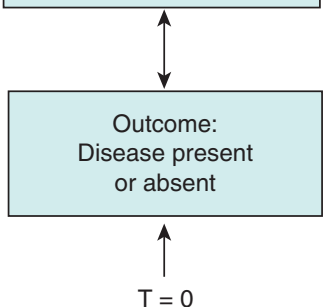

Predictors:

Patient characteristics

Disease characteristics

Imaging tests

Laboratory tests

Others
Cross-sectional

relationship

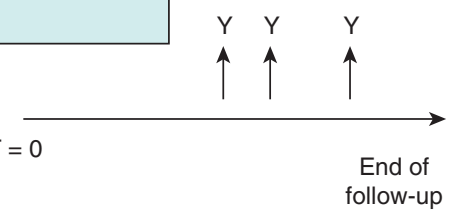

\section{Box B. Similarities and differences between diagnostic and prognostic prediction models}

Despite the different nature (timing) of the prediction, there are many similarities between diagnostic and prognostic prediction models, including:

- Type of outcome is often binary: either disease of interest present versus absent (in diagnosis) or the future occurrence of an event yes or no (in prognosis)

- The key interest is to generate the probability of the outcome being present or occurring for an individual, given the values of 2 or more predictors, with the purpose of informing patients and guiding clinical decision making.

- The same challenges as when developing a multivariable prediction model, such as selection of the predictors, model-building strategies, and handling of continuous predictors and the danger of overfitting.

- $\quad$ The same measures for assessing model performance.

Different terms for similar features between diagnostic and prognostic modeling studies are summarized below.

Diagnostic Prediction Modeling Study

Diagnostic tests or index tests

\section{Explanatory variables, predictors, covariates ( $X$ variables)}

Outcome (Y variable)

Target disease/disorder (presence vs. absence)

Reference standard and disease verification

Partial verification
Prognostic Prediction Modeling Study

Prognostic factors or indicators

Event (future occurrence: yes or no) Event definition and event measurement

Loss to follow-up and censoring 
models include the Framingham Risk Score (Anderson et al, 1991), Ottawa Ankle Rules (Stiell et al, 1992), EuroScore (Nashef et al, 1999), Nottingham Prognostic Index (Haybittle et al, 1982), and the Simplified Acute Physiology Score (Le Gall et al, 1984).

\section{PREDICTION MODEL STUDIES}

Prediction model studies can be broadly categorised as model development (Royston et al, 2009), model validation (with or without updating) (Moons et al, 2012a), or a combination of both (Figure 1). Model development studies aim to derive a prediction model by selecting the relevant predictors and combining them statistically into a multivariable model. Logistic and Cox regression are most frequently used for short-term (e.g., disease absent vs present, 30-day mortality) and long-term (e.g., 10-year risk) outcomes, respectively (Justice et al, 1999; Steyerberg et al, 2001b; Altman et al, 2009; Royston et al, 2009; Moons et al, $2012 a, b)$. Studies may also focus on quantifying the incremental or added predictive value of a specific predictor (e.g., newly discovered) to a prediction model (Steyerberg et al, 2012).

Quantifying the predictive ability of a model on the same data from which the model was developed (often referred to as apparent performance) will tend to give an optimistic estimate of performance, owing to overfitting (too few outcome events relative to the number of candidate predictors) and the use of predictor

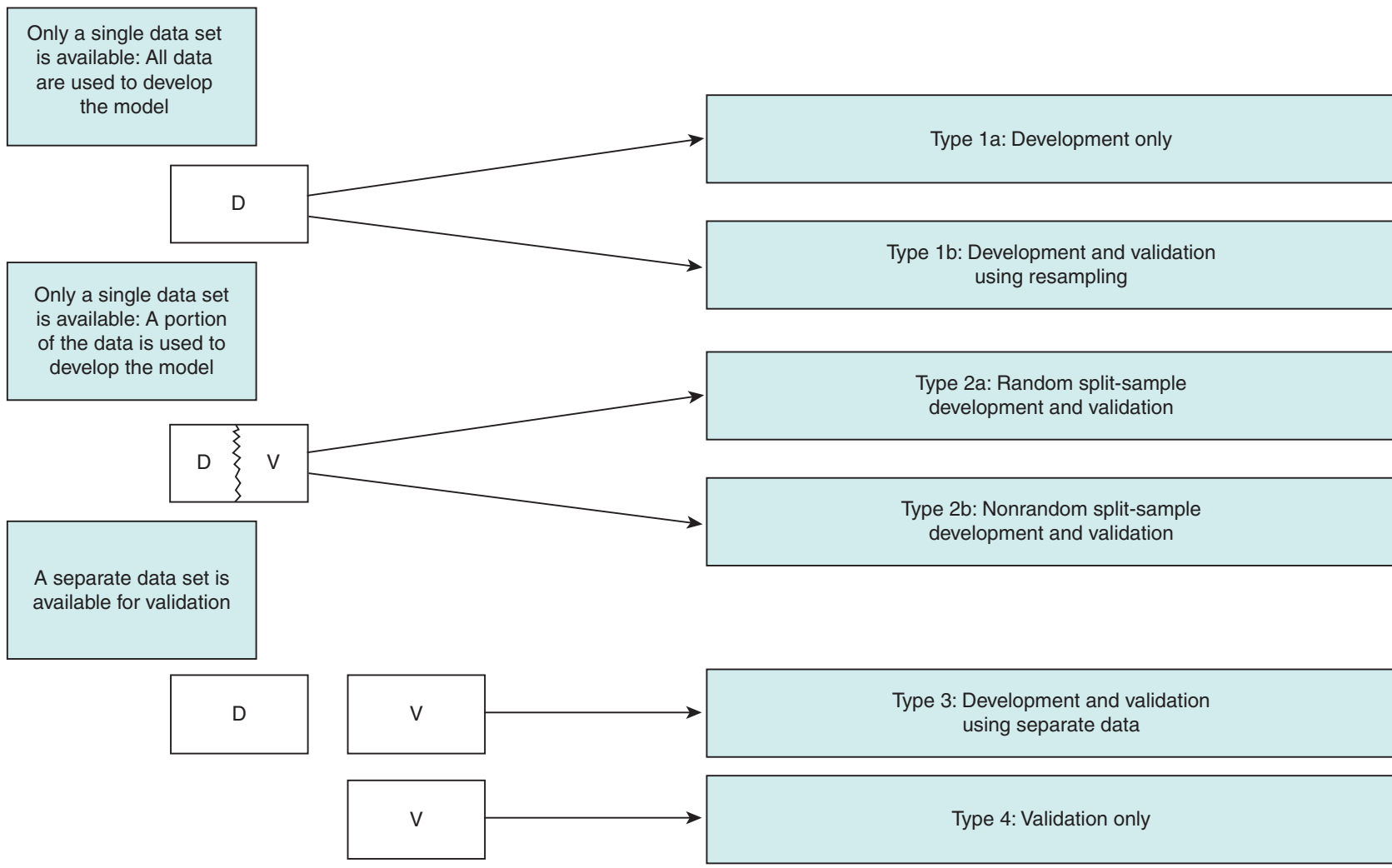

\footnotetext{
Analysis

Analysis Description
Type
}

Type 1a Development of a prediction model where predictive performance is then directly evaluated using exactly the same data (apparent performance).

Type 1b Development of a prediction model using the entire data set, but then using resampling (e.g., bootstrapping or cross-validation) techniques to evaluate the performance and optimism of the developed model. Resampling techniques, generally referred to as 'internal validation', are recommended as a prerequisite for prediction model development, particularly if data are limited $(6,14,15)$.

Type 2a The data are randomly split into two groups: one to develop the prediction model, and one to evaluate its predictive performance. This design is generally not recommended or better than type $1 \mathrm{~b}$, particularly in case of limited data, because it leads to lack of power during model development and validation $(14,15,16)$.

Type $2 \mathrm{~b} \quad$ The data are nonrandomly split (e.g., by location or time) into two groups: one to develop the prediction model and one to evaluate its predictive performance. Type $2 \mathrm{~b}$ is a stronger design for evaluating model performance than type $2 \mathrm{a}$, because it allows for nonrandom variation between the 2 data sets $(6,13,17)$.

Type 3 Development of a prediction model using one data set and an evaluation of its performance on separate data (e.g., from a different study).

Type 4 The evaluation of the predictive performance of an existing (published) prediction model on separate data (13).

Types 3 and 4 are commonly referred to as 'external validation studies.' Arguably, type $2 \mathrm{~b}$ is as well, although it may be considered an intermediary between internal and external validation.

Figure 1. Types of prediction model studies covered by the TRIPOD statement. $\mathrm{D}=$ development data; $\mathrm{V}=$ validation data. 
selection strategies (Steyerberg et al, 2003). Studies developing new prediction models should therefore always include some form of internal validation to quantify any optimism in the predictive performance (e.g., calibration and discrimination) of the developed model. Internal validation techniques use only the original study sample and include such methods as bootstrapping or crossvalidation. Internal validation is a necessary part of model development (Steyerberg, 2009). Overfitting, optimism, and miscalibration may also be addressed and accounted for during the model development by applying shrinkage (e.g., heuristic or based on bootstrapping techniques) or penalisation procedures (e.g., ridge regression or lasso) (Steyerberg et al, 2001a).

After developing a prediction model, it is strongly recommended to evaluate the performance of the model in other participant data than was used for the model development. Such external validation requires that for each individual in the new data set, outcome predictions are made using the original model (i.e., the published regression formula) and compared with the observed outcomes (Altman et al, 2009; Moons et al, 2012a). External validation may use participant data collected by the same investigators, typically using the same predictor and outcome definitions and measurements, but sampled from a later period (temporal or narrow validation); by other investigators in another hospital or country, sometimes using different definitions and measurements (geographic or broad validation); in similar participants but from an intentionally different setting (e.g., model developed in secondary care and assessed in similar participants but selected from primary care); or even in other types of participants (e.g., model developed in adults and assessed in children, or developed for predicting fatal events and assessed for predicting nonfatal events) (Justice et al, 1999; Reilly and Evans, 2006; Wallace et al, 2011; Moons et al, 2012a, 2012b). In case of poor performance, the model can be updated or adjusted on the basis of the validation data set (Moons et al, 2012a).

REPORTING OF MULTIVARIABLE PREDICTION MODEL STUDIES

Studies developing or validating a multivariable prediction model share specific challenges for researchers (Steyerberg et al, 2013). Several reviews have evaluated the quality of published reports that describe the development or validation prediction models (Laupacis et al, 1997; Mallett et al, 2010; Collins et al, 2011; Bouwmeester et al, 2012; Collins et al, 2013, 2014). For example, Mallett et al (2010) examined 47 reports published in 2005 presenting new prediction models in cancer. Reporting was found to be poor, with insufficient information described in all aspects of model development, from descriptions of patient data to statistical modeling methods. Collins et al (2011) evaluated the methodological conduct and reporting of 39 reports published before May 2011 describing the development of models to predict prevalent or incident type 2 diabetes. Reporting was also found to be generally poor, with key details on which predictors were examined, the handling and reporting of missing data, and model-building strategy often poorly described. Bouwmeester et al (2012) evaluated 71 reports, published in 2008 in six high-impact general medical journals, and likewise observed an overwhelmingly poor level of reporting. These and other reviews provide a clear picture that, across different disease areas and different journals, there is a generally poor level of reporting of prediction model studies (Laupacis et al, 1997; Ettema et al, 2010; Mallett et al, 2010; Collins et al, 2011; Bouwmeester et al, 2012; Collins et al, 2013; Steyerberg et al, 2013; Collins et al, 2014). Furthermore, these reviews have shown that serious deficiencies in the statistical methods, use of small data sets, inappropriate handling of missing data, and lack of validation are common (Laupacis et al, 1997; Ettema et al, 2010;
Mallett et al, 2010; Collins et al, 2011; Bouwmeester et al, 2012; Collins et al, 2013; Steyerberg et al, 2013; Collins et al, 2014). Such deficiencies ultimately lead to prediction models that are not or should not be used. It is therefore not surprising, and fortunate, that very few prediction models, relative to the large number of models published, are widely implemented or used in clinical practice (Steyerberg et al, 2013).

Prediction models in medicine have proliferated in recent years. Health-care providers and policy makers are increasingly recommending the use of prediction models within clinical practice guidelines to inform decision making at various stages in the clinical pathway (Rabar et al, 2012; Goff et al, 2014). It is a general requirement of reporting of research that other researchers can, if required, replicate all the steps taken and obtain the same results (Laine et al, 2007). It is therefore essential that key details of how a prediction model was developed and validated be clearly reported to enable synthesis and critical appraisal of all relevant information (Knottnerus, 1995; Altman et al, 2009; Collins and Moons, 2012; Seel et al, 2012; Siontis et al, 2012).

REPORTING GUIDELINES FOR PREDICTION MODEL STUDIES: THE TRIPOD STATEMENT

We describe the development of the TRIPOD (Transparent Reporting of a multivariable prediction model for Individual Prognosis or Diagnosis) Statement, a guideline specifically designed for the reporting of studies developing or validating a multivariable prediction model, whether for diagnostic or prognostic purposes. TRIPOD is not intended for multivariable modeling in etiologic studies or for studies investigating single prognostic factors (McShane et al, 2005). Furthermore, TRIPOD is also not intended for impact studies that quantify the impact of using a prediction model on participant or doctors' behavior and management, participant health outcomes, or cost-effectiveness of care, compared with not using the model (Moons et al, 2009a, 2012a).

Reporting guidelines for observational (the STrengthening the Reporting of OBservational studies in Epidemiology (STROBE)) (von Elm et al, 2007), tumor marker (REporting recommendations for tumour MARKer prognostic studies (REMARK)) (McShane et al, 2005), diagnostic accuracy (STAndards for the Reporting of Diagnostic accuracy studies (STARD)) (Bossuyt et al, 2003), and genetic risk prediction (Genetic RIsk Prediction Studies (GRIPS)) (Janssens et al, 2011b) studies all contain many items that are relevant to studies developing or validating prediction models. However, none of these guidelines are entirely appropriate for prediction model studies. The two guidelines most closely related to prediction models are REMARK and GRIPS. However, the focus of the REMARK checklist is primarily on prognostic factors and not prediction models, whereas the GRIPS statement is aimed at risk prediction using genetic risk factors and the specific methodological issues around handling large numbers of genetic variants.

To address a broader range of studies, we developed the TRIPOD guideline: Transparent Reporting of a multivariable prediction model for Individual Prognosis or Diagnosis. TRIPOD explicitly covers the development and validation of prediction models for both diagnosis and prognosis, for all medical domains and all types of predictors. TRIPOD also places much more emphasis on validation studies and the reporting requirements for such studies. The reporting of studies evaluating the incremental value of specific predictors, beyond established predictors or even beyond existing prediction models (Tzoulaki et al, 2011; Steyerberg et al, 2012), also fits entirely within the remit of TRIPOD (see the accompanying explanation and elaboration document (Moons et al, 2015), available at www.annals.org). 


\section{DEVELOPING THE TRIPOD STATEMENT}

We convened a 3-day meeting with an international group of prediction model researchers, including statisticians, epidemiologists, methodologists, health-care professionals, and journal editors (from Annals of Internal Medicine, BMJ, Journal of Clinical Epidemiology, and PLoS Medicine) to develop recommendations for the TRIPOD Statement.

We followed published guidance for developing reporting guidelines and established a steering committee (Drs Collins, Reitsma, Altman, and Moons) to organise and coordinate the development of TRIPOD (Moher et al, 2010). We conducted a systematic search of MEDLINE, EMBASE, PsychINFO, and Web of Science to identify any published articles making recommendations on reporting of multivariable prediction models (or aspects of developing or validating a prediction model), reviews of published reports of multivariable prediction models that evaluated methodological conduct or reporting and reviews of methodological conduct and reporting of multivariable models in general. From these studies, a list of 129 possible checklist items was generated. The steering committee then merged related items to create a list of 76 candidate items.

Twenty-five experts with a specific interest in prediction models were invited by e-mail to participate in the Web-based survey and to rate the importance of the 76 candidate checklist items. Respondents (24 of 27) included methodologists, health-care professionals, and journal editors. (In addition to the 25 meeting participants, the survey was also completed by 2 statistical editors from Annals of Internal Medicine.)

The results of the survey were presented at a 3-day meeting in June 2011, in Oxford, United Kingdom; it was attended by 24 of the 25 invited participants (22 of whom had participated in the survey). During the 3-day meeting, each of the 76 candidate checklist items was discussed in turn, and a consensus was reached on whether to retain, merge with another item, or omit the item. Meeting participants were also asked to suggest additional items. After the meeting, the checklist was revised by the steering committee during numerous face-to-face meetings, and circulated to the participants to ensure it reflected the discussions. While making revisions, conscious efforts were made to harmonise our recommendations with other reporting guidelines, and where possible we chose the same or similar wording for items (McShane et al, 2005; von Elm et al, 2007; Little et al, 2009; Moher et al, 2009; Janssens et al, 2011b).

\section{TRIPOD COMPONENTS}

The TRIPOD Statement is a checklist of 22 items that we consider essential for good reporting of studies developing or validating multivariable prediction models (Table 1). The items relate to the title and abstract (items 1 and 2), background and objectives (item 3), methods (items 4 through 12), results (items 13 through 17), discussion (items 18 through 20), and other information (items 21 and 22). The TRIPOD Statement covers studies that report solely development (Royston et al, 2009, Moons et al, 2012 b), both development and external validation, and solely external validation (with or without updating), of a prediction model (Altman et al, 2009) (Figure 1). Therefore, some items are relevant only for studies reporting the development of a prediction model (items 10a, 10b, 14, and 15), and others apply only to studies reporting the (external) validation of a prediction model (items $10 \mathrm{c}, 10 \mathrm{e}, 12,13 \mathrm{c}, 17$, and 19a). All other items are relevant to all types of prediction model development and validation studies. Items relevant only to the development of a prediction model are denoted by $D$, items relating solely to a validation of a prediction model are denoted by $V$, whereas items relating to both types of study are denoted $D ; V$.

The recommendations within TRIPOD are guidelines only for reporting research and do not prescribe how to develop or validate a prediction model. Furthermore, the checklist is not a quality assessment tool to gauge the quality of a multivariable prediction model.

An ever-increasing number of studies are evaluating the incremental value of specific predictors, beyond established predictors or even beyond existing prediction models (Tzoulaki et al, 2011; Steyerberg et al, 2012). The reporting of these studies fits entirely within the remit of TRIPOD (see accompanying explanation and elaboration document (Moons et al, 2015).

\section{THE TRIPOD EXPLANATION AND ELABORATION DOCUMENT}

In addition to the TRIPOD Statement, we produced a supporting explanation and elaboration document (Moons et al, 2015) in a similar style to those for other reporting guidelines (Vandenbroucke et al, 2007; Janssens et al, 2011a; Altman et al, 2012). Each checklist item is explained and accompanied by examples of good reporting from published articles. In addition, because many such studies are methodologically weak, we also summarise the qualities of good (and the limitations of less good) studies, regardless of reporting (Moons et al, 2015). A comprehensive evidence base from existing systematic reviews of prediction models was used to support and justify the rationale for including and illustrating each checklist item. The development of the explanation and elaboration document was completed after several face-to-face meetings, teleconferences, and iterations among the authors. Additional revisions were made after sharing the document with the whole TRIPOD group before final approval.

\section{ROLE OF THE FUNDING SOURCE}

There was no explicit funding for the development of this checklist and guidance document. The consensus meeting in June 2011 was partially funded by a National Institute for Health Research Senior Investigator Award held by Dr Altman, Cancer Research UK, and the Netherlands Organization for Scientific Research. Drs Collins and Altman are funded in part by the Medical Research Council. Dr Altman is a member of the Medical Research Council Prognosis Research Strategy (PROGRESS) Partnership. The funding sources had no role in the study design, data collection, analysis, preparation of the manuscript, or decision to submit the manuscript for publication.

\section{DISCUSSION}

Many reviews have showed that the quality of reporting in published articles describing the development or validation of multivariable prediction models in medicine is poor (Laupacis et al, 1997; Ettema et al, 2010; Mallett et al, 2010; Collins et al, 2011; Bouwmeester et al, 2012; Collins et al, 2013, 2014). In the absence of detailed and transparent reporting of the key study details, it is difficult for the scientific and health-care community to objectively judge the strengths and weaknesses of a prediction model study (Collins and Michaëlsson, 2012; Seel et al, 2012; Järvinen et al, 2014). The explicit aim of this checklist is to improve the quality of reporting of published prediction model studies. The TRIPOD guideline has been developed to support authors in writing reports describing the development, validation, or updating of prediction models, aid editors and peer reviewers in reviewing 
Table 1. Checklist of items to include when reporting a study developing or validating a multivariable prediction model for diagnosis or prognosis ${ }^{a}$

\begin{tabular}{|l|r|c|}
\hline Section/topic & Item & $\begin{array}{c}\text { Development } \\
\text { or validation? }\end{array}$ \\
\hline Title and abstract \\
\hline Title & 1 & $\mathrm{D} ; \mathrm{V}$ \\
Abstract & 2 & $\mathrm{D} ; \mathrm{V}$ \\
\hline
\end{tabular}

Checklist item

\section{Introduction}

Background and

objectives

$\mathrm{D} \cdot \mathrm{V}$

Identify the study as developing and/or validating a multivariable prediction model, the target population, and the outcome to be predicted.

Provide a summary of objectives, study design, setting, participants, sample size, predictors, outcome, statistical analysis, results, and conclusions.

\begin{tabular}{|c|c|c|}
\hline \\
\hline & $3 b$ & $\mathrm{D} ; \mathrm{V}$ \\
\hline \multicolumn{3}{|l|}{ Methods } \\
\hline \multirow[t]{2}{*}{ Source of data } & $4 a$ & $\mathrm{D} ; \mathrm{V}$ \\
\hline & $4 b$ & $\mathrm{D} ; \mathrm{V}$ \\
\hline \multirow[t]{3}{*}{ Participants } & $5 a$ & $\mathrm{D} ; \mathrm{V}$ \\
\hline & $5 b$ & $\mathrm{D} ; \mathrm{V}$ \\
\hline & $5 c$ & $\mathrm{D} ; \mathrm{V}$ \\
\hline \multirow[t]{2}{*}{ Outcome } & $6 a$ & $D ; V$ \\
\hline & $6 b$ & $\mathrm{D} ; \mathrm{V}$ \\
\hline \multirow[t]{2}{*}{ Predictors } & $7 a$ & $\mathrm{D} ; \mathrm{V}$ \\
\hline & $7 b$ & $\mathrm{D} ; \mathrm{V}$ \\
\hline Sample size & 8 & $\mathrm{D} ; \mathrm{V}$ \\
\hline Missing data & 9 & $\mathrm{D} ; \mathrm{V}$ \\
\hline \multirow{5}{*}{$\begin{array}{l}\text { Statistical } \\
\text { analysis } \\
\text { methods }\end{array}$} & $10 a$ & $\mathrm{D}$ \\
\hline & $10 b$ & $\mathrm{D}$ \\
\hline & $10 c$ & $\mathrm{~V}$ \\
\hline & $10 d$ & $\mathrm{D} ; \mathrm{V}$ \\
\hline & $10 \mathrm{e}$ & $\mathrm{V}$ \\
\hline Risk groups & 11 & $D ; V$ \\
\hline $\begin{array}{l}\text { Development vs } \\
\text { validation }\end{array}$ & 12 & V \\
\hline
\end{tabular}

Explain the medical context (including whether diagnostic or prognostic) and rationale for developing or validating the multivariable prediction model, including references to existing models. Specify the objectives, including whether the study describes the development or validation of the model, or both.

Describe the study design or source of data (e.g., randomised trial, cohort, or registry data), separately for the development and validation data sets, if applicable.

Specify the key study dates, including start of accrual; end of accrual; and, if applicable, end of follow-up. Specify key elements of the study setting (e.g., primary care, secondary care, general population) including number and location of centres.

Describe eligibility criteria for participants.

Give details of treatments received, if relevant.

Clearly define the outcome that is predicted by the prediction model, including how and when assessed. Report any actions to blind assessment of the outcome to be predicted.

Clearly define all predictors used in developing the multivariable prediction model, including how and when they were measured.

Report any actions to blind assessment of predictors for the outcome and other predictors.

Explain how the study size was arrived at.

Describe how missing data were handled (e.g., complete-case analysis, single imputation, multiple imputation) with details of any imputation method.

Describe how predictors were handled in the analyses.

Specify type of model, all model-building procedures (including any predictor selection), and method for internal validation.

For validation, describe how the predictions were calculated.

Specify all measures used to assess model performance and, if relevant, to compare multiple models. Describe any model updating (e.g., recalibration) arising from the validation, if done.

Provide details on how risk groups were created, if done.

For validation, identify any differences from the development data in setting, eligibility criteria, outcome, and predictors.

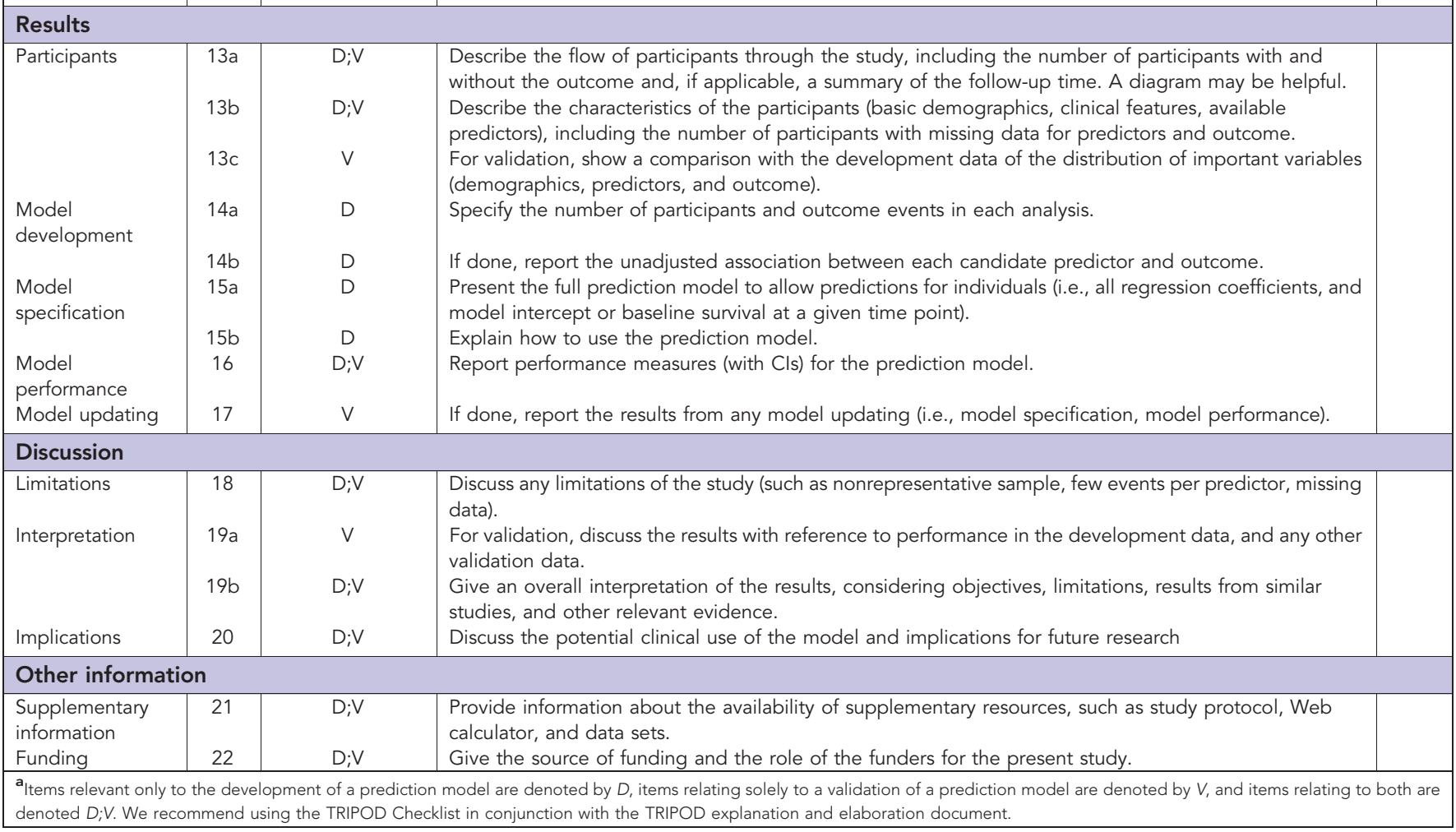


manuscripts submitted for publication, and help readers in critically appraising published reports.

The TRIPOD Statement does not prescribe how studies developing, validating, or updating prediction models should be undertaken, nor should it be used as a tool for explicitly assessing quality or quantifying risk of bias in such studies (Moons et al, 2014). There is, however, an implicit expectation that authors have an appropriate study design and conducted certain analyses to ensure all aspects of model development and validation are reported. The accompanying explanation and elaboration document describes aspects of good practice for such studies, as well as highlighting some inappropriate approaches that should be avoided (Moons et al, 2015).

TRIPOD encourages complete and transparent reporting reflecting study design and conduct. It is a minimum set of information that authors should report to inform the reader about how the study was carried out. We are not suggesting a standardised structure of reporting, rather that authors should ensure that they address all the checklist items somewhere in their article with sufficient detail and clarity.

We encourage researchers to develop a study protocol, especially for model development studies, and even register their study in registers that accommodate observational studies (such as ClinicalTrials.gov) (Hemingway et al, 2009; Williams et al, 2010). The importance of also publishing protocols for developing or validating prediction models, certainly when conducting a prospective study, is slowly being acknowledged (Stiell et al, $2002 \mathrm{a}, \mathrm{b})$. Authors can also include the study protocol when submitting their article for peer review, so that readers can know the rationale for including individuals into the study or whether all of the analyses were prespecified.

To help the editorial process, peer reviewers, and, ultimately, readers, we recommend submitting the checklist as an additional file with the report, indicating the pages where information for each item is reported. The TRIPOD reporting template for the checklist can be downloaded from www.tripod-statement.org.

Announcements and information relating to TRIPOD will be broadcasted on the TRIPOD Twitter address (@TRIPOD Statement). The Enhancing the QUAlity and Transparency Of health Research (EQUATOR) Network (www.equator-network.org) will help disseminate and promote the TRIPOD Statement.

Methodological issues in developing, validating, and updating prediction models evolve. TRIPOD will be periodically reappraised, and if necessary, modified to reflect comments, criticisms, and any new evidence. We therefore encourage readers to make suggestions for future updates so that ultimately, the quality of prediction model studies will improve.

\section{ACKNOWLEDGEMENTS}

Grant Support: There was no explicit funding for the development of this checklist and guidance document. The consensus meeting in June 2011 was partially funded by a National Institute for Health Research Senior Investigator Award held by Dr. Altman, Cancer Research UK (grant C5529), and the Netherlands Organization for Scientific Research (ZONMW 918.10.615 and 91208004). Drs Collins and Altman are funded in part by the Medical Research Council (grant G1100513). Dr Altman is a member of the Medical Research Council Prognosis Research Strategy (PROGRESS) Partnership (G0902393/99558).

\section{EDITOR'S NOTE}

In order to encourage dissemination of the TRIPOD Statement, this article is freely accessible on the Annals of Internal Medicine
Web site (www.annals.org) and will be also published in BJOG, British Journal of Cancer, British Journal of Surgery, BMC Medicine, British Medical Journal, Circulation, Diabetic Medicine, European Journal of Clinical Investigation, European Urology, and Journal of Clinical Epidemiology. The authors jointly hold the copyright of this article. An accompanying Explanation and Elaboration article is freely available only on www.annal.org; Annals of Internal Medicine holds copyright for that article. For contributors to the TRIPOD Statement, see the Appendix 1 (available at www.annals.org).

\section{CONFLICT OF INTEREST}

The authors declare no conflicts of interest.

\section{AUTHOR CONTRIBUTIONS}

Conception and design: G.S. Collins, J.B. Reitsma, D.G. Altman, K.G.M. Moons. Analysis and interpretation of the data: G.S. Collins, D.G. Altman, K.G.M. Moons. Drafting of the article: G.S. Collins, J.B. Reitsma, D.G. Altman, K.G.M. Moons. Critical revision of the article for important intellectual content: G.S. Collins, J.B. Reitsma, D.G. Altman, K.G.M. Moons. Final approval of the article: G.S. Collins, J.B. Reitsma, D.G. Altman, K.G.M. Moons. Provision of study materials or patients: G.S. Collins, K.G.M. Moons. Statistical expertise: G.S. Collins, J.B. Reitsma, D.G. Altman, K.G.M. Moons. Obtaining of funding: G.S. Collins, D.G. Altman, K.G.M. Moons. Administrative, technical, or logistic support: G.S. Collins, K.G.M. Moons. Collection and assembly of data: G.S. Collins, D.G. Altman, K.G.M. Moons.

\section{REFERENCES}

Altman DG, McShane LM, Sauerbrei W, Taube SE (2012) Reporting recommendations for tumor marker prognostic studies (REMARK): explanation and elaboration. BMC Med 10: 51.

Altman DG, Vergouwe Y, Royston P, Moons KGM (2009) Prognosis and prognostic research: Validating a prognostic model. BMJ 338: b605.

Anderson KM, Odell PM, Wilson PWF, Kannel WB (1991) Cardiovascular disease risk profiles. Am Heart J 121: 293-298.

Bossuyt PM, Reitsma JB, Bruns DE, Gatsonis CA, Glasziou PP, Irwig LM, Lijmer JG, Moher D, Rennie D, de Vet HC (2003) Towards complete and accurate reporting of studies of diagnostic accuracy: The STARD Initiative. Radiology 226: 24-28.

Bouwmeester W, Zuithoff NP, Mallett S, Geerlings MI, Vergouwe Y, Steyerberg EW, Altman DG, Moons KG (2012) Reporting and methods in clinical prediction research: a systematic review. PLoS Med 9: 1-12.

Collins GS, de Groot JA, Dutton S, Omar O, Shanyinde M, Tajar A, Voysey M, Wharton R, Yu LM, Moons KG, Altman DG (2014) External validation of multivariable prediction models: a systematic review of methodological conduct and reporting. BMC Med Res Methodol 14: 40.

Collins GS, Mallett S, Omar O, Yu LM (2011) Developing risk prediction models for type 2 diabetes: a systematic review of methodology and reporting. BMC Med 9: 103.

Collins GS, Michaëlsson K (2012) Fracture risk assessment: state of the art, methodologically unsound, or poorly reported? Curr Osteoporos Rep 10: 199-207.

Collins GS, Moons KG (2012) Comparing risk prediction models. BMJ 344: e3186.

Collins GS, Omar O, Shanyinde M, Yu LM (2013) A systematic review finds prediction models for chronic kidney were poorly reported and often developed using inappropriate methods. J Clin Epidemiol 66: 268-277.

Dorresteijn JA, Visseren FL, Ridker PM, Wassink AM, Paynter NP, Steyerberg EW, van der Graaf Y, Cook NR (2011) Estimating treatment effects for individual patients based on the results of randomised clinical trials. BMJ 343: d5888. 
Ettema RG, Peelen LM, Schuurmans MJ, Nierich AP, Kalkman CJ, Moons KG (2010) Prediction models for prolonged intensive care unit stay after cardiac surgery: systematic review and validation study. Circulation 122: 682-689.

Goff DC, Lloyd-Jones DM, Bennett G, Coady S, D’Agostino RB, Gibbons R, Greenland P, Lackland DT, Levy D, O'Donnell CJ, Robinson J, Schwartz JS, Shero ST, Smith SC, Sorlie P, Stone NJ, Wilson PW, Jordan HS, Nevo L, Wnek J, Anderson JL, Halperin JL, Albert NM, Bozkurt B, Brindis RG, Curtis LH, DeMets D, Hochman JS, Kovacs RJ, Ohman EM, Pressler SJ, Sellke FW, Shen WK, Smith Jr SC, Tomaselli GF (2014) 2013 ACC/AHA Guideline on the Assessment of Cardiovascular Risk: A Report of the American College of Cardiology/American Heart Association Task Force on Practice Guidelines. Circulation 129: S49-S73.

Haybittle JL, Blamey RW, Elston CW, Johnson J, Doyle PJ, Campbell FC, Nicholson RI, Griffiths K (1982) A prognostic index in primary breast cancer. Br J Cancer 45: 363-366.

Hayward RA, Kent DM, Vijan S, Hofer TP (2006) Multivariable risk prediction can greatly enhance the statistical power of clinical trial subgroup analysis. BMC Med Res Methodol 6: 18.

Hemingway H, Riley RD, Altman DG (2009) Ten steps towards improving prognosis research. BMJ 339: b4184.

Janssens AC, Ioannidis JP, Bedrosian S, Boffetta P, Dolan SM, Dowling N, Fortier I, Freedman AN, Grimshaw JM, Gulcher J, Gwinn M, Hlatky MA, Janes H, Kraft P, Melillo S, O’Donnell CJ, Pencina MJ, Ransohoff D, Schully SD, Seminara D, Winn DM, Wright CF, van Duijn CM, Little J, Khoury MJ (2011a) Strengthening the reporting of genetic risk prediction studies (GRIPS): explanation and elaboration. Eur J Clin Invest 41: 10101035.

Janssens AC, Ioannidis JP, van Duijn CM, Little J, Khoury MJ (2011b) Strengthening the reporting of genetic risk prediction studies: the GRIPS statement. Eur J Clin Invest 41: 1004-1009.

Järvinen TL, Jokihaara J, Guy P, Alonso-Coello P, Collins GS, Michaëlsson K, Sievänen H (2014) Conflicts at the heart of the FRAX tool. CMAJ 185: $165-167$.

Justice AC, Covinsky KE, Berlin JA (1999) Assessing the generalizability of prognostic information. Ann Intern Med 130: 515-524.

Knottnerus JA (1995) Diagnostic prediction rules: principles, requirements and pitfalls. Prim Care 22: 341-363.

Laine C, Goodman SN, Griswold ME, Sox HC (2007) Reproducible research: moving toward research the public can really trust. Ann Intern Med 146: 450-453.

Laupacis A, Sekar N, Stiell IG (1997) Clinical prediction rules. A review and suggested modifications of methodological standards. JAMA 277: 488-494.

Le Gall JR, Loirat P, Alperovitch A, Glaser P, Granthil C, Mathieu D, Mercier P, Thomas R, Villers D (1984) A simplified acute physiology score for ICU patients. Crit Care Med 12: 975-977.

Little J, Higgins JP, Ioannidis JP, Moher D, Gagnon F, von Elm E, Khoury MJ, Cohen B, Davey-Smith G, Grimshaw J, Scheet P, Gwinn M, Williamson RE, Zou GY, Hutchings K, Johnson CY, Tait V, Wiens M, Golding J, van Duijn C, McLaughlin J, Paterson A, Wells G, Fortier I, Freedman M, Zecevic M, King R, Infante-Rivard C, Stewart A, Birkett N (2009) STrengthening the REporting of Genetic Association Studies (STREGA): an extension of the STROBE statement. PLoS Med 6: e22.

Mallett S, Royston P, Dutton S, Waters R, Altman DG (2010) Reporting methods in studies developing prognostic models in cancer: a review. BMC Med 8: 20.

McShane LM, Altman DG, Sauerbrei W, Taube SE, Gion M, Clark GM (2005) Reporting recommendations for tumor marker prognostic studies (REMARK). J Natl Cancer Inst 97: 1180-1184.

Moher D, Liberati A, Tetzlaff J, Altman DG (2009) Preferred reporting items for systematic reviews and meta-analyses: the PRISMA statement. Ann Intern Med 151: 264-269.

Moher D, Schulz KF, Simera I, Altman DG (2010) Guidance for developers of health research reporting guidelines. PLoS Med 16: e1000217.

Moons KG, de Groot JA, Bouwmeester W, Vergouwe Y, Mallett S, Altman DG, Reitsma JB, Collins GS (2014) Critical Appraisal and Data Extraction for Systematic Reviews of Prediction Modelling Studies: The CHARMS Checklist. PLoS Med 11(10): e1001744.

Moons KG, Kengne AP, Grobbee DE, Royston P, Vergouwe Y, Altman DG, Woodward M (2012a) Risk prediction models: II. External validation, model updating, and impact assessment. Heart 98: 691-698.

Moons KG, Kengne AP, Woodward M, Royston P, Vergouwe Y, Altman DG, Grobbee DE (2012b) Risk prediction models: I. Development, internal validation, and assessing the incremental value of a new (bio)marker. Heart 98: 683-690.

Moons KGM, Altman DG, Reitsma JB, Ioannidis JPA, Macaskill P, Steyerberg EW, Vickers AJ, Ransohoff DF, Collins GS (2015) Transparent Reporting of a multivariable prediction model for Individual Prognosis Or Diagnosis (TRIPOD): Explanation and Elaboration. Ann Intern Med 162: W1-W73.

Moons KGM, Altman DG, Vergouwe Y, Royston P (2009a) Prognosis and prognostic research: application and impact of prognostic models in clinical practice. BMJ 338: b606.

Moons KGM, Royston P, Vergouwe Y, Grobbee DE, Altman DG (2009b) Prognosis and prognostic research: what, why, and how? BMJ 338: b375.

Nashef SA, Roques F, Michel P, Gauducheau E, Lemeshow S, Salamon R (1999) European system for cardiac operative risk evaluation (EuroSCORE). Eur J Cardiothorac Surg 16: 9-13.

Rabar S, Lau R, O'Flynn N, Li L, Barry P (2012) Risk assessment of fragility fractures: summary of NICE guidance. BMJ 345: e3698.

Reilly BM, Evans AT (2006) Translating clinical research into clinical practice: impact of using prediction rules to make decisions. Ann Intern Med 144: 201-209.

Riley RD, Hayden JA, Steyerberg EW, Moons KG, Abrams K, Kyzas PA, Malats N, Briggs A, Schroter S, Altman DG, Hemingway H (2013) Prognosis Research Strategy (PROGRESS) 2: prognostic factor research. PLoS Med 10: e1001380.

Royston P, Moons KGM, Altman DG, Vergouwe Y (2009) Prognosis and prognostic research: Developing a prognostic model. BMJ 338: b604.

Seel RT, Steyerberg EW, Malec JF, Sherer M, Macciocchi SN (2012) Developing and evaluating prediction models in rehabilitation populations. Arch Phys Med Rehabil 93: S138-S153.

Siontis GC, Tzoulaki I, Siontis KC, Ioannidis JP (2012) Comparisons of established risk prediction models for cardiovascular disease: systematic review. BMJ 344: e3318.

Steyerberg EW (2009) Clinical prediction models: a practical approach to development, validation, and updating. Springer: New York.

Steyerberg EW, Bleeker SE, Moll HA, Grobbee DE, Moons KGM (2003) Internal and external validation of predictive models: A simulation study of bias and precision in small samples. J Clin Epidemiol 56: 441-447.

Steyerberg EW, Eijkemans MJC, Habbema JDF (2001a) Application of shrinkage techniques in logistic regression analysis: a case study. Statistica Neerlandica 55: 76-88.

Steyerberg EW, Harrell FE, Borsboom GJJM, Eijkemans MJC, Vergouwe Y, Habbema JDF (2001b) Internal validation of predictive models: efficiency of some procedures for logistic regression analysis. J Clin Epidemiol 54: 774-781.

Steyerberg EW, Moons KGM, van der Windt DA, Hayden JA, Perel P, Schroter S, Riley RD, Hemingway H, Altman DG (2013) Prognosis Research Strategy (PROGRESS) 3: Prognostic Model Research. PLoS Med 10: e1001381.

Steyerberg EW, Pencina MJ, Lingsma HF, Kattan MW, Vickers AJ, Van Calster B (2012) Assessing the incremental value of diagnostic and prognostic markers: a review and illustration. Eur J Clin Invest 42: 216-228.

Stiell IG, Greenberg GH, McKnight RD, Nair RC, McDowell I, Worthington JR (1992) A study to develop clinical decision rules for the use of radiography in acute ankle injuries. Ann Emerg Med 21: 384-390.

Stiell IG, Wells GA, McKnight D, Brison R, Lesiuk H, Clement CM, Eisenhauer MA, Greenberg GH, MacPhail I, Reardon M, Worhington J, Verbeek R, Dreyer J, Cass D, Schull M, Morrison L, Rowe B, Holroyd B, Bandiera G, Laupacis A (2002a) Canadian C-Spine Rule study for alert and stable trauma patients: I. Background and rationale. CJEM 4: 84-90.

Stiell IG, Wells GA, McKnight D, Brison R, Lesiuk H, Clement CM, Eisenhauer MA, Greenberg GH, MacPhail I, Reardon M, Worhington J, Verbeek R, Dreyer J, Cass D, Schull M, Morrison L, Rowe B, Holroyd B, Bandiera G, Laupacis A (2002b) Canadian C-Spine Rule study for alert and stable trauma patients: II. Study objectives and methodology. CJEM 4: 185-193.

Tzoulaki I, Liberopoulos G, Ioannidis JP (2011) Use of reclassification for assessment of improved prediction: an empirical evaluation. Int $J$ Epidemiol 40: 1094-1105.

Vandenbroucke JP, von Elm E, Altman DG, Gøtzsche PC, Mulrow CD, Pocock SJ, Poole C, Schlesselman JJ, Egger M (2007) Strengthening the Reporting of Observational Studies in Epidemiology (STROBE): explanation and elaboration. Epidemiology 18: 805-835. 
von Elm E, Altman DG, Egger M, Pocock SJ, Gøtzsche PC, Vandenbroucke JP (2007) Strengthening the Reporting of Observational Studies in Epidemiology (STROBE) statement: guidelines for reporting observational studies. BMJ 335: 806-808.

Wallace E, Smith SM, Perera-Salazar R, Vaucher P, McCowan C, Collins G, Verbakel J, Lakhanpaul M, Fahey T (2011) Framework for the impact analysis and implementation of Clinical Prediction Rules (CPRs). BMC Med Inform Decis Mak 11: 62.

\section{APPENDIX 1}

Appendix 1 Members of the TRIPOD Group

Gary Collins (University of Oxford, Oxford, United Kingdom); Douglas Altman (University of Oxford, Oxford, United Kingdom); Karel Moons (University Medical Center Utrecht, Utrecht, The Netherlands); Johannes Reitsma (University Medical Center Utrecht, Utrecht, the Netherlands); Virginia Barbour (PLoS Medicine, United Kingdom and Australia); Nancy Cook (Division of Preventive Medicine, Brigham \& Women's Hospital, Boston, Massachusetts); Joris de Groot (University Medical Center Utrecht, Utrecht, The Netherlands); Trish Groves (BMJ, London, United Kingdom); Frank Harrell, Jr. (Vanderbilt University, Nashville, Tennessee); Harry Hemingway (University College London, London, United Kingdom); John Ioannidis (Stanford University, Stanford, California); Michael W. Kattan (Cleveland Clinic,
Williams RJ, Tse T, Harlan WR, Zarin DA (2010) Registration of observational studies: Is it time? CMAJ 182: 1638-1642.

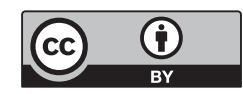

This work is licensed under the Creative Commons Attribution 4.0 International License. To view a copy of this license, visit http://creativecommons.org/licenses/by/4.0/

Cleveland, Ohio); André Knottnerus (Maastricht University, Maastricht, The Netherlands, and Journal of Clinical Epidemiology); Petra Macaskill (University of Sydney, Sydney, Australia); Susan Mallett (University of Oxford, Oxford, United Kingdom); Cynthia Mulrow (Annals of Internal Medicine, American College of Physicians, Philadelphia, Pennsylvania); David Ransohoff (University of North Carolina at Chapel Hill, Chapel Hill, North Carolina); Richard Riley (University of Birmingham, Birmingham, United Kingdom); Peter Rothwell (University of Oxford, Oxford, United Kingdom); Patrick Royston (Medical Research Council Clinical Trials Unit at University College London, London, United Kingdom); Willi Sauerbrei (University of Freiburg, Freiburg, Germany); Ewout Steyerberg (University Medical Center Rotterdam, Rotterdam, the Netherlands); Ian Stiell (University of Ottawa, Ottawa, Ontario, Canada); Andrew Vickers (Memorial Sloan Kettering Cancer Center, New York). 